\title{
Correction: mHealth-Supported Delivery of an Evidence-Based Family Home-Visiting Intervention in Sierra Leone: Protocol for a Pilot Randomized Controlled Trial
}

\author{
Alethea Desrosiers ${ }^{1}, \mathrm{PhD}$; Carolyn Schafer ${ }^{1}, \mathrm{MPH}$; Rebecca Esliker ${ }^{2}, \mathrm{PhD}$; Musu Jambai ${ }^{3}, \mathrm{BA}$; Theresa S Betancourt ${ }^{1}$, \\ $\mathrm{ScD}$
}

${ }^{1}$ Boston College, School of Social Work, Chestnut Hill, MA, United States

${ }^{2}$ University of Makeni, Makeni, Sierra Leone

${ }^{3}$ Caritas Freetown, Freetown, Sierra Leone

\section{Corresponding Author:}

Alethea Desrosiers, PhD

Boston College

School of Social Work

140 Commonwealth Avenue

Chestnut Hill, MA, 01778

United States

Phone: 16175528398

Email: alethea.desrosiers@bc.edu

\section{Related Article:}

Correction of: https://www.researchprotocols.org/2021/2/e25443

(JMIR Res Protoc 2021;10(2):e27711) doi: 10.2196/27711

In "mHealth-Supported Delivery of an Evidence-Based Family Home-Visiting Intervention in Sierra Leone: Protocol for a Pilot Randomized Controlled Trial" (JMIR Res Protoc 2021;10(2):e25443) the authors noted one error.

The name of the last author in the originally published paper was listed as "Theresa Betancourt". This has been corrected to "Theresa S Betancourt".
The correction will appear in the online version of the paper on the JMIR Publications website on February 4, 2021, together with the publication of this correction notice. Because this was made after submission to PubMed, PubMed Central, and other full-text repositories, the corrected article has also been resubmitted to those repositories.

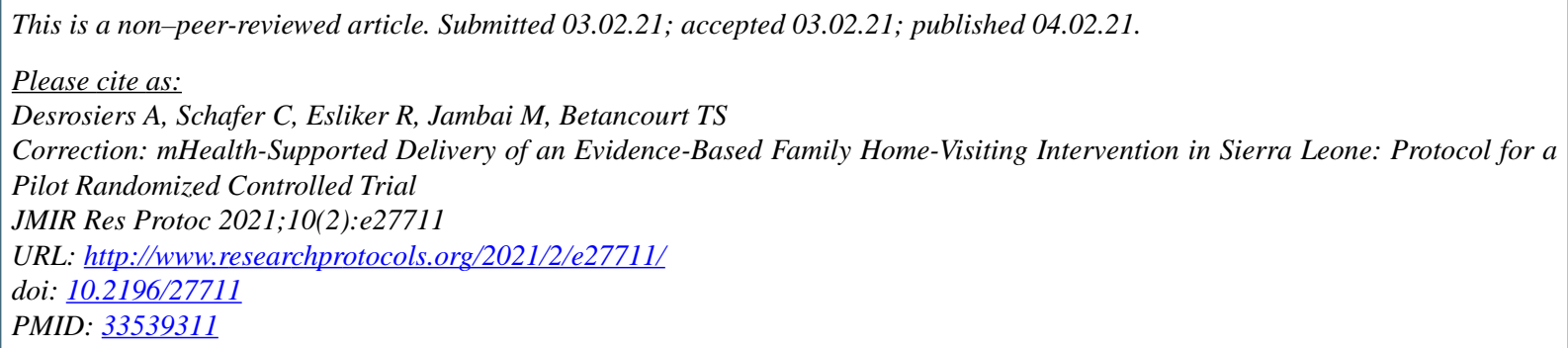

CAlethea Desrosiers, Carolyn Schafer, Rebecca Esliker, Musu Jambai, Theresa S Betancourt. Originally published in JMIR Research Protocols (http://www.researchprotocols.org), 04.02.2021. This is an open-access article distributed under the terms of the Creative Commons Attribution License (https://creativecommons.org/licenses/by/4.0/), which permits unrestricted use, distribution, and reproduction in any medium, provided the original work, first published in JMIR Research Protocols, is properly cited. The complete bibliographic information, a link to the original publication on http://www.researchprotocols.org, as well as this copyright and license information must be included. 